\title{
Changing Subsistence Practices at the Dorset Paleoeskimo Site of Phillip's Garden, Newfoundland
}

\author{
Lisa M. Hodgetts, M. A. P. Renouf, Maribeth S. Murray, \\ Darlene McCuaig-Balkwill, and Lesley Howse
}

\begin{abstract}
A comparison of identified faunal assemblages from the Dorset site of Phillip's Garden indicates that harp seal hunting was the main focus of activity throughout the site's occupation. Despite the highly specialized nature of site use, it appears that reliance on harp seal decreased over time while fish and birds became increasingly important. These changes may reflect longer seasonal occupations at the site in later centuries, and/or a decrease in the local availability of harp seal. The observed shift coincides with the onset of a local climatic warming trend, which might have affected harp seal movements in the area. Dorset subsistence and settlement patterns in Newfoundland are still poorly understood due to a lack of preserved faunal assemblages in the region. The temporal trend illustrated here indicates that we cannot assume that these patterns were static throughout the Dorset occupation of the island.
\end{abstract}

\section{Introduction}

The Dorset Paleoeskimo have often been distinguished from earlier Paleoeskimo groups by their larger site size, more substantial dwelling structures, and thicker midden deposits (see Maxwell 1985:197; McGhee 1990:63-68, 1996:139; Renouf 1993:202). The Dorset site of Phillip's Garden (EeBi-1), on the northwest coast of Newfoundland (Fig. 1), represents an extreme expression of this trend. An intensively occupied seal hunting camp, it is the largest known Dorset site in Newfoundland, and one of the largest reported in the eastern Arctic (Renouf 1993:198). Over 50 house depressions are visible on the ground surface, and a total of at least 70 houses is estimated based on a recent magnetometer survey of the site (Eastaugh 2002). Radiocarbon dates on charcoal range between $2140 \pm 100$ B.P. (Beta-23976) and $1321 \pm 49$ B.P. (P-737) (Fig. 2), indicating that the site was in use for a 700-year period.

Previous discussions of the faunal remains from Phillip's Garden have highlighted the specialized nature of subsistence activities at the site. Several analysts illustrate the dominance of seal remains, in particular those of harp seal, among the excavated faunal collections from the site (Harp 1976; Linehan 1990; Murray 1992; Renouf 2000, 2002; Renouf and Murray 1999). Their work

Lisa M. Hodgetts, M. A. P. Renouf, and Lesley Howse

Archaeology Unit, Memorial University of Newfoundland, St. John's NL, A1C 5S7 Canada Maribeth S. Murray, Department of Anthropology,

University of Alaska Fairbanks, Fairbanks, AK 99775-7720 Darlene McCuaig-Balkwill

Canadian Museum of Nature, Ottawa ON, K1P 6P4 Canada 
implies a near-exclusive reliance on harp seal throughout the occupation of Phillip's Garden. However, a recently excavated midden feature contains an unusually large proportion of fish and bird bone, suggesting that subsistence practices varied at the site over the course of its occupation (Hodgetts 2002). For the first time, the faunal data from different phases of occupation at Phillip's Garden have been synthesized, in order to examine the possibility of subsistence change through time at the site.

\section{Harp Seal-The Prey of Choice}

The intensity of occupation at Phillip's Garden, and the narrow focus of hunting activity that took place there is, no doubt, related to the large numbers of harp seals that concentrate in the area each spring. Harp seals move through the Strait of Belle Isle, which separates Newfoundland's Northern Peninsula from Labrador and Quebec, twice each year (Sergeant 1991). In December, they move southward from the Arctic to their breeding grounds in the Gulf of St. Lawrence. Harp seals are found on the Newfoundland side only occasionally at this time, and are reported to be more common on the Quebec side of the Strait (LeBlanc 1996:26-27, 2000a:24). The return migration takes place in April and May, when seals move north along with the retreating pack ice (Fig. 3). At this time, they are available in large numbers near Phillip's Garden (LeBlanc 1996:28-36, 2000a:26).

The Point Riche Peninsula, where Phillip's Garden is situated, occupies a unique position with respect to the movements of harp seals (LeBlanc 1996, 2000a). Harp seal prey species, and therefore harp seals, concentrate in the waters close to the site. Harp seals feed directly on planktonic organisms, particularly Euphasiids. They also feed on species further up the food chain, which themselves feed on Euphasiids. Of particular importance in this regard are capelin (Mallotus villosus), the harp seal's most important prey species in subarctic waters, and northern shrimp (Pandalus borealis) (Sergeant 1991:65-70). All of these harp seal prey species are most abundant in areas of marine upwelling, where large communities of plankton are found (LeBlanc 1996:32-35; Parsons 1980). Such upwelling occurs along the steep edges of deep-water channels, such as the Esquiman Channel off the west coast of Newfoundland (Fig. 4). When the Gulf of St. Lawrence harp seal population resumes feeding after the moult, individuals concentrate along the
Esquiman Channel where their prey are most abundant (LeBlanc 2000a:26). Less than one kilometer away, the Point Riche Peninsula at Port au Choix is the closest point of land along the channel's entire length (Fig. 4). During their spring migration, concentrations of harp seals are therefore found closer to Port au Choix than anywhere else on the west coast of Newfoundland or the Quebec Lower North Shore (LeBlanc 1996, 2000a). This unique situation probably accounts for the development of the unusually large Dorset site at Phillip's Garden.

\section{Faunal Evidence from Phillip's Garden}

This analysis is restricted to reasonably large faunal assemblages from midden features that have produced charcoal-based radiocarbon dates. Faunal remains have been recovered from both midden deposits and dwelling features at Phillip's Garden. Because of the different formation processes involved, however, the two types of assemblages are not directly comparable. Middens are secondary or tertiary refuse deposits that contain bone from animal carcasses that have been processed (often extensively) elsewhere. The animal bone from a dwelling reflects the food preparation and consumption activities that took place within, but is also the product of human trampling and cleaning episodes. In order to reduce the number of confounding factors influencing the data, only the midden assemblages, which are more numerous and generally larger than the dwelling assemblages, will be examined. Samples deemed too small to be representative have been excluded from this study. Amorosi et al. (1996: 132-134) examine the influence of sample size on the relative proportions of major taxa (defined as those which together account for 60-80 percent of the total) in midden assemblages from the Norse western settlement of Greenland. They demonstrate that once the NISP for the major taxa reaches 300-400, further increases in sample size do not significantly alter the relative percentages of these taxa. Phocids are the dominant taxon in all of the Phillip's Garden assemblages. Therefore, a minimum sample size of 400 seal specimens was set for this analysis.

Five assemblages meet the criteria outlined above. All exceed the minimum sample size, containing over 900 seal specimens each. They were collected from the following middens (Fig. 5): Feature $49^{1}$, dated to1890 \pm 90 B.P. (Beta-42967), 


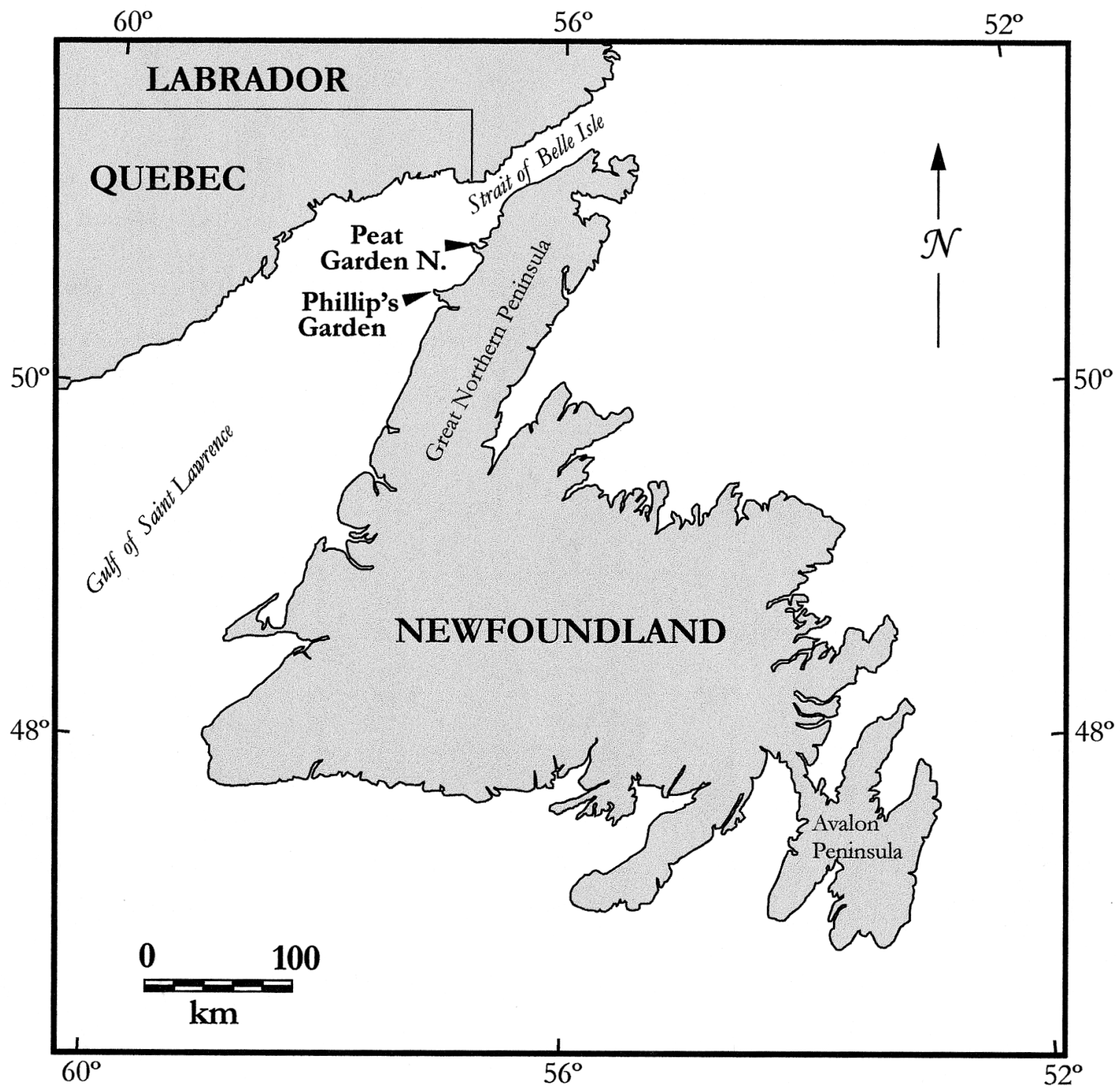

Figure 1. Location of Phillip's Garden and other sites referred to in the text.

Feature $52^{2}$, dated to $1770 \pm 120$ B.P. (Beta-42968), Feature $77^{3}$, dated to $1640 \pm 70$ B.P. (Beta-160975), Feature $2 \mathrm{~T}^{4}$, dated to $1520 \pm 90$ B.P. (Beta-19084), and Feature $73^{5}$, which has produced three radiocarbon dates: $1490 \pm 40$ B.P. (Beta-160976), $1370 \pm 90$ B.P. (Beta-66436), and $1360 \pm 80$ B.P.

(Beta-160977).

These assemblages were identified by four different analysts with access to different reference collections. However, because of the large sample sizes, and because this research focuses on temporal changes in very broad taxonomic categories (fish, bird, and seal), it is unlikely that inter-observer error has significantly influenced the results. Amorosi et al. (1996:139-142) demonstrated highly significant correlations between the relative proportions of taxonomic categories in assemblages identified by different analysts. This was true both when two analysts identified different sub-samples of the same assemblage, and when two analysts identified different assemblages from sites of similar cultural affiliation, location, size, period, and social status. In both cases, "any individual differences, or differences in recording system, were overwhelmed by the patterning inherent in the data" (Amorosi et al. 1996:141).

Figure 2 shows the temporal relationship between the middens under consideration and all other available radiocarbon dates from Phillip's Garden. The selected faunal assemblages fall into 


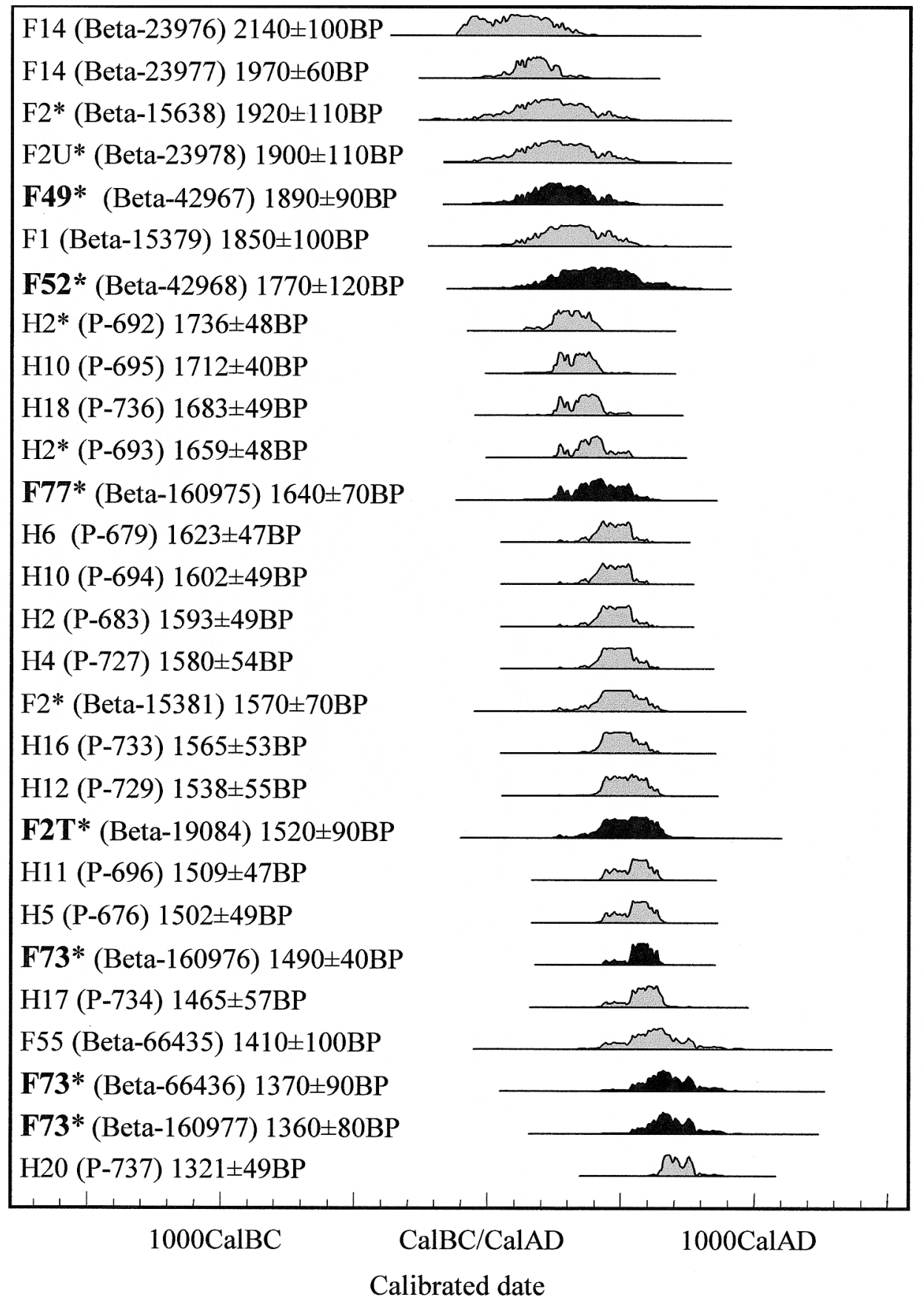

Figure 2. All charcoal-based radiocarbon dates from Phillip's Garden. Dates for assemblages used in this analysis are highlighted. Middens are starred; all other features are house depressions. Calibration based on Stuiver et al. (1998) and plotted by OxCal v. 3.5 (Bronk Ramsey 2000).

three periods of occupation at Phillip's Garden. Feature 49 represents the initial stages of occupation at the site. Features 52 and 77 were created during the middle period of occupation, when the site appears to have been used most intensively
(Erwin 1995; Renouf and Murray 1999:130). Feature $2 \mathrm{~T}$ and Feature 73 were created towards the end of the site's use.

Figure 6 presents the relative proportions of various faunal classes in the study assemblages. 


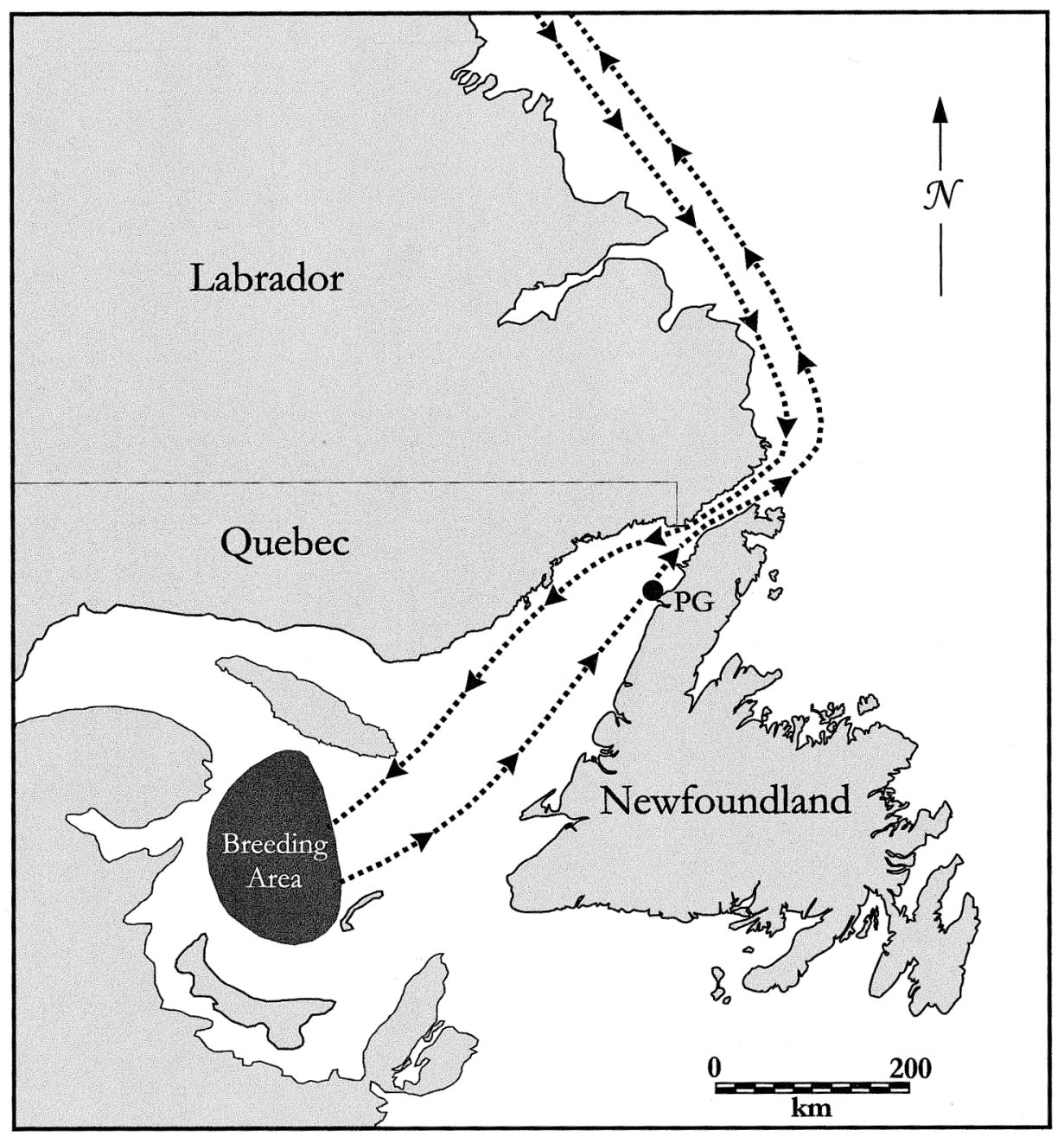

Figure 3. Migration routes of the Gulf of St. Lawrence harp seal breeding population.

The percentages were calculated based on NISP counts for all identifiable material. Seal bone is difficult to identify to species because of the high degree of morphological variation within species, and the many similarities between species. In the assemblages in question, harp seal comprises between $92.5 \%$ and $100 \%$ of the seal bone that could be positively identified to species. The vast majority of bones in the general "seal" category are probably also harp seal.

These data illustrate the overwhelming importance of harp seal throughout the occupation of Phillip's Garden; seal is the dominant category in all five assemblages. The proportion of seal remains is extremely high, and remarkably consistent, in the three earliest assemblages. At Feature 49 , seals comprise $96.1 \%$ of the identified faunal material, at Feature 52 they make up 99.4\%, and at Feature 77 they account for $97.6 \%$. Fish, bird, and tiny amounts of whale and terrestrial mammal bone make up the remainder of these assemblages. The percentage of seal among the identified faunal remains is noticeably smaller in the other two assemblages. It drops to $81.4 \%$ at Feature 2T, where fish comprise 9.4\%, birds $8.9 \%$, and other mammals $0.3 \%$ of the assemblage. At Feature 73, the proportion of seal is even lower, at $70.8 \%$. Fish, found only rarely elsewhere on the site, make up $25.1 \%$ of the identified specimens from this midden. Birds make up an additional $3.8 \%$, other mammals another $0.3 \%$. Note that the "other mammal" category is not visible in Figure 6 because it makes up less than $0.5 \%$ of each assemblage. Thus, 


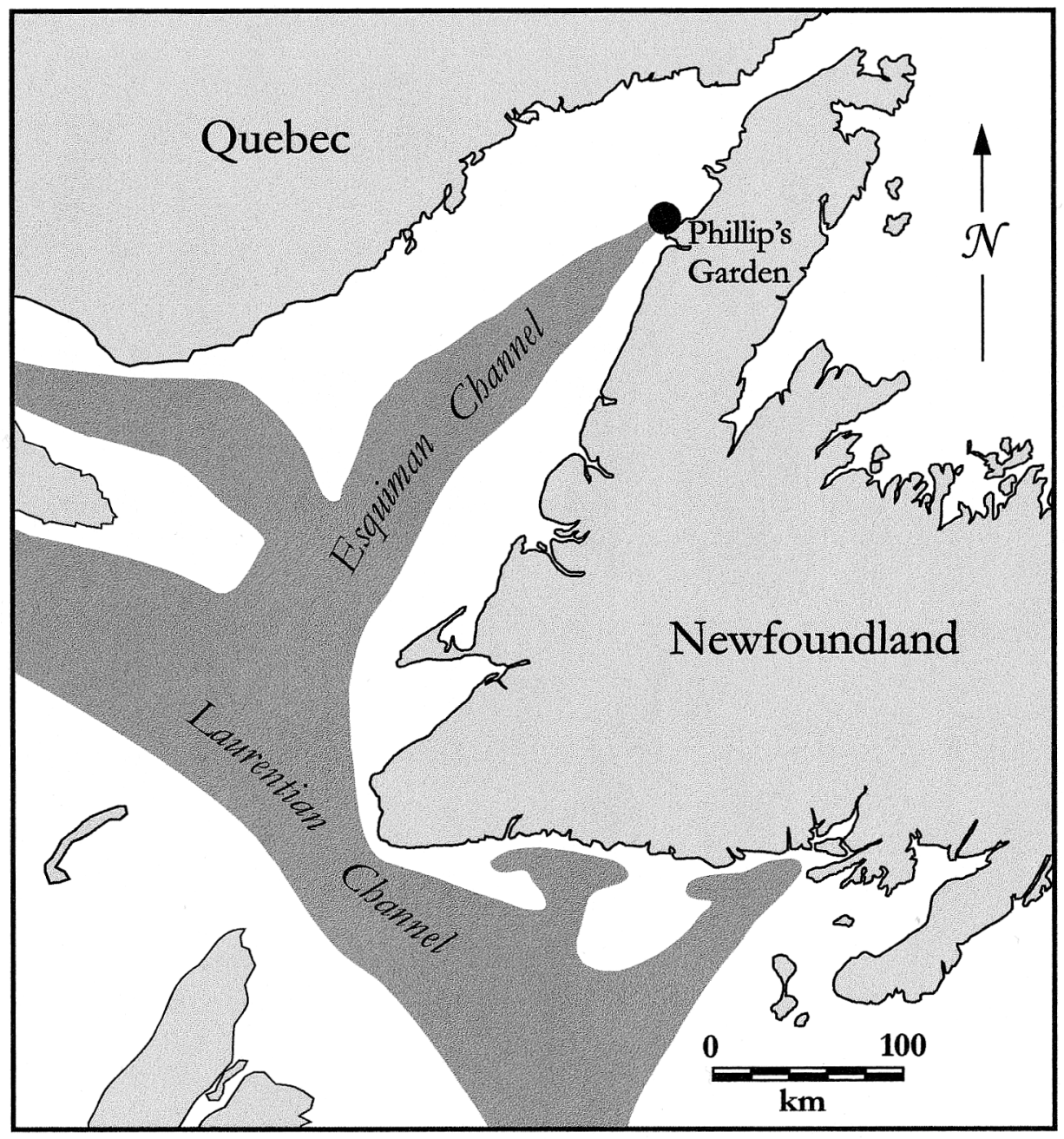

Figure 4. Location of Esquiman Channel.

there is an increase in the importance of non-seal taxa through time.

Figure 7, which presents the 95\% confidence intervals (established using Student's $t$-distribution) for the percentage of non-seal taxa within each of the assemblages, highlights this trend. There is no overlap between any of the error ranges, indicating that there are significant differences (at the 0.05 level) in the proportion of nonseal taxa in all five assemblages. This is not unexpected, as these middens represent different occupational episodes. There are, however, striking similarities between the three earliest assemblages, where non-seal taxa comprise less than $5 \%$. There is a marked increase in non-seal taxa in the later assemblages, to over $15 \%$ in the assemblage from Feature 2T, and over 25\% in Feature 73.

There are several potential explanations for the noticeably larger percentages of fish and bird bone in the faunal material from Features 2T and 73 than in any of the other assemblages. Archaeological recovery methods may have played a role and/or conditions for the preservation of fish and bird bone may have been more favourable within Feature 2T and Feature 73 than elsewhere on the site. The larger proportion of non-seal taxa could also be attributed to a different season of occupation, or a change in the availability of harp seals in the area. Each of these options will be addressed in turn.

\section{Recovery and Preservation}

Excavation methods were consistent across the site. All excavated material was dry sieved through $4 \mathrm{~mm}$ mesh. A 10\% sample from each deposit within every $1 \mathrm{~m}^{2}$ excavation unit was wet screened through $0.5 \mathrm{~mm}$ mesh. Differential recovery can 


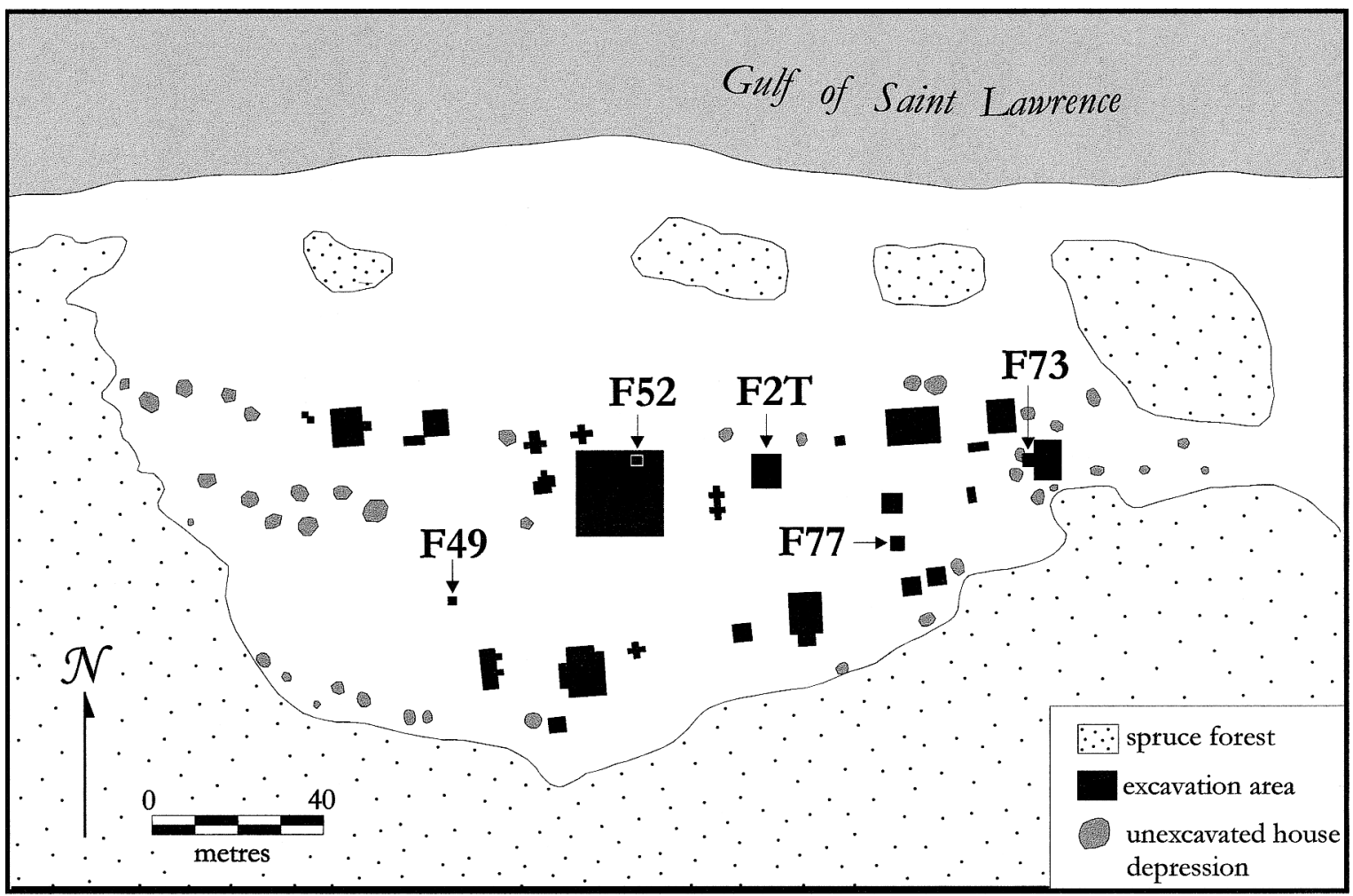

Figure 5. Phillip's Garden site map.

atherefore be ruled out as an explanation for the markedly different proportions of fish and bird bone in the assemblages under discussion.

Although bone preservation is unusual on sites in Newfoundland because of the slow development and acidic nature of the soils across the island, there is excellent bone preservation at Phillip's Garden, as attested by the presence of fragile fish, bird, and juvenile seal bones in all of the assemblages in question. This results partly from the limestone bedrock of the Port au Choix area, which buffers the acidic peat above. The large volume of material deposited at the site no doubt also contributes to the excellent preservation. A midden deposit creates its own anaerobic micro-environment, and thereby promotes the preservation of organic material.

Nonetheless, ratios of identified to unidentified fragments indicate that preservation conditions were not consistent across the site. Given that weathering, fragmentation, and decomposition will all have a negative impact on the ability to identify archaeological bone, the ratio of identified to unidentified fragments is taken here as a proxy measure of the level of preservation within an assemblage. This technique cannot be applied to all archaeological bone assemblages since factors other than preservation conditions can also bring about a high degree of fragmentation. Human groups frequently process terrestrial mammal bones, particularly those of large-bodied animals such as caribou, in order to extract marrow and grease. However, seal bones dominate the Phillip's Garden assemblages, and their structure makes it extremely difficult to extract marrow and grease. Seal longbone shafts lack the marrow cavities found in terrestrial mammals, and are filled instead with cancellous bone. Any digestible matter is therefore dispersed in tiny pockets throughout the bone, making it difficult to remove. Seal bone grease is also difficult to extract because it is liquid at room temperature. It cannot be released by boiling and can only be rendered at low temperatures using modern technical equipment (Shahidi et al. 1994). Numerous archaeological examples indicate that pinniped bones are rarely processed by humans, and are generally far more complete than ungulate bones from the same sites (CruzUribe and Klein 1994; Hodgetts 1999; Lyman 1991). Thus, in the case of Phillip's Garden, where 


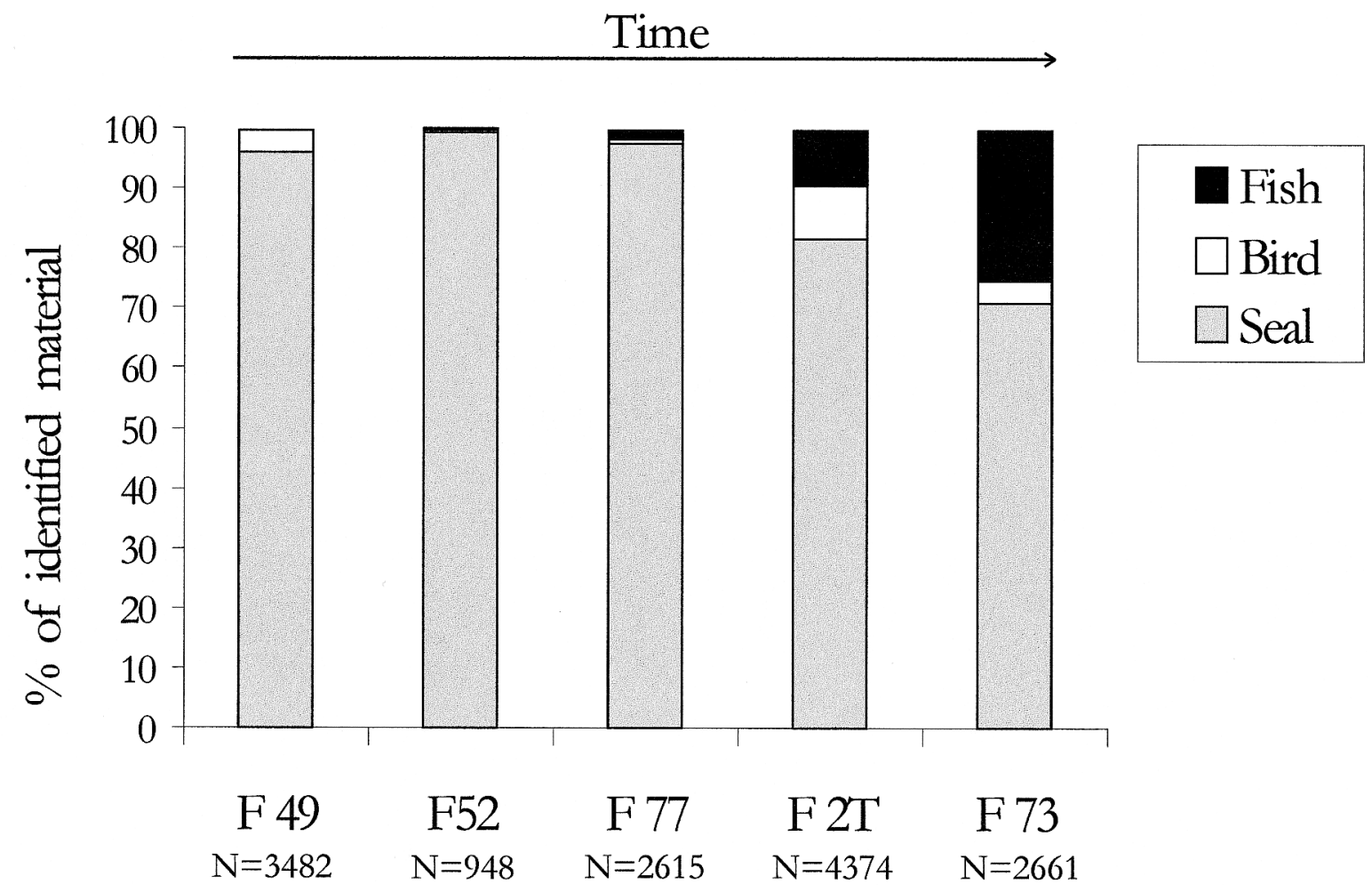

Figure 6. Relative proportions of main faunal categories at Phillip's Garden (based on total identified NISP).

Table 1. Ratios of identified to unidentified fragments (NISP).

\begin{tabular}{lccc}
\hline Site and Feature & Identified $^{*}$ & Unidentified & Ratio \\
\hline Phillip's Garden & & & \\
Feature 49 & 3,419 & 6,392 & 0.53 \\
Feature 52 & 948 & 2,898 & 0.33 \\
Feature 77 & 1,363 & 2,370 & 0.58 \\
Feature 2T & 4,376 & 24,339 & 0.18 \\
Feature 73 & 1,977 & 4,676 & 0.43 \\
\hline
\end{tabular}

* Specimens in this category could be identified to element (or broad element category such as longbone or vertebra) and to at least the Class level.

seal remains comprise the bulk of the faunal samples and there is no indication of carnivore activity, fragmentation is likely to be a product of natural destructive agents. The ratio of identifiable to unidentifiable fragments therefore reflects preservation conditions; the higher the ratio, the better the preservation. Table 1 presents these ratios for the Phillip's Garden assemblages.

Given the fragile nature of many fish and bird bones, a positive correlation would be expected between their numbers and the ratios in Table 1 if preservation conditions accounted for the importance of the three main taxonomic groups within each assemblage. Instead, Feature 49 and Feature 77 , which have the two highest ratios of identified to unidentified fragments ( 0.53 and 0.58 respectively), have considerably smaller proportions of fish and bird bone than either Feature 2T or Feature 73, both of which have much lower ratios ( 0.18 and 0.43 respectively). Spearman's rank order correlation coefficient indicates a weak negative correlation between the proportion of fish and bird remains in each assemblage and the ratio of identified to unidentified fragments, but it is not significant at the 0.1 level $\left(r_{s}=-0.245, p>0.20\right)$. Clearly, the two variables are not positively correlated. This 


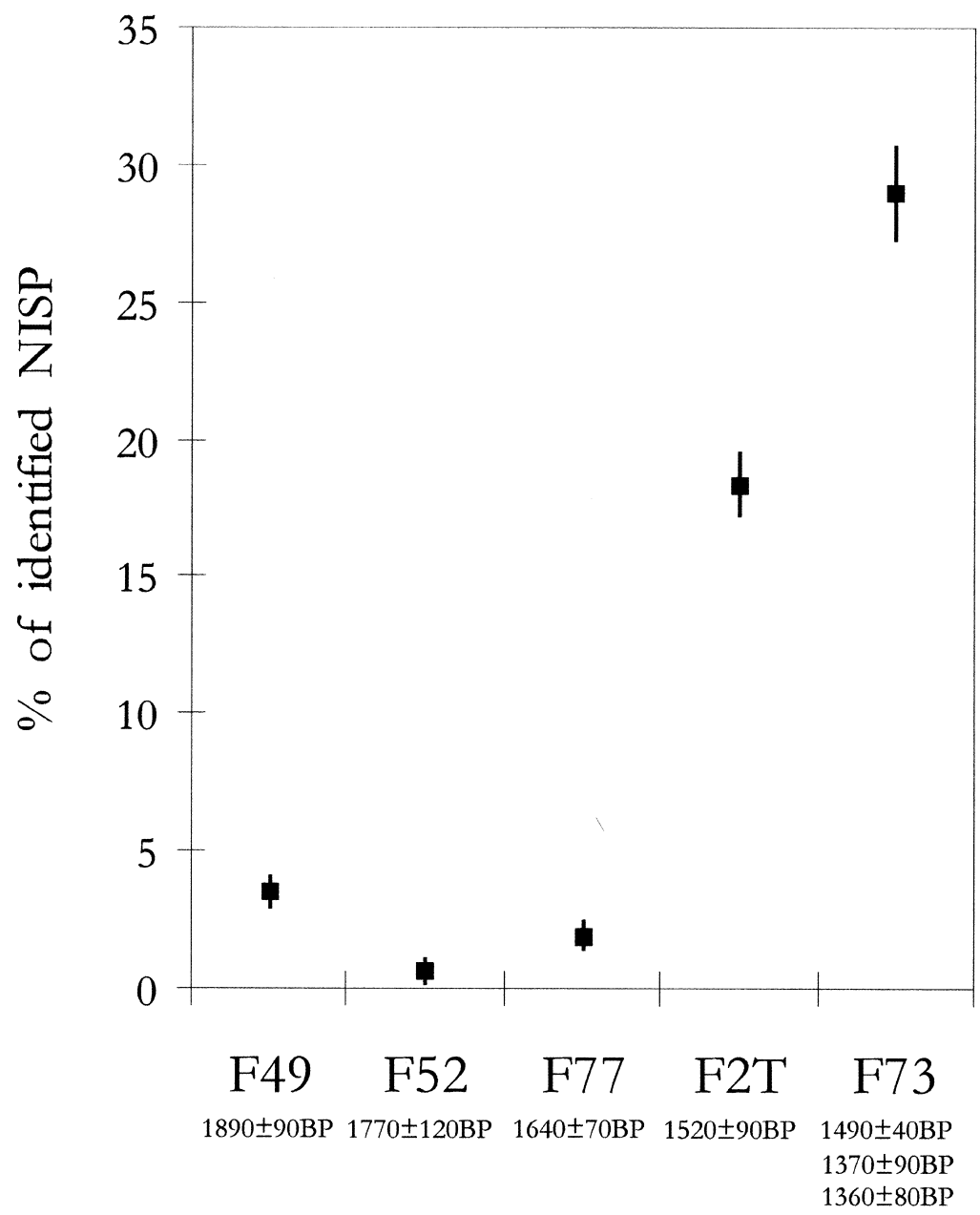

Figure 7. Relative importance of non-seal taxa in the Phillip's Garden middens (error bars indicate 95\% confidence limits; the standard error was established using Student's $t$-distribution).

suggests that the increase in non-seal taxa over time is a real phenomenon, not a product of preservation. Our data may actually underestimate the importance of fish and bird in the two later features (2T and 73 ) relative to the earlier ones (49, 77 , and to a lesser degree 52) because the later assemblages appear generally less well-preserved.

\section{Seasonality}

Another potential explanation for the different proportions of seal and non-seal taxa in these assemblages is that they represent different seasons of activity. The presence of juvenile seal bone in all of the features under discussion indicates that seals were hunted in the spring, shortly after the birth of the newborn seals. A December harp seal hunt during the southward migration has also been demonstrated on the basis of measurement data at Feature 49, Feature 77, Feature 2T, and Feature 73 (Hodgetts, in press a and b), and remains a strong possibility at Feature 52, though it has yet to be conclusively demonstrated. The relative importance of these two hunts cannot be assessed based on the measurement data given the current sample sizes (Hodgetts, in press b), but the vast quantities of harp seal remains from these features suggest a tendency to exploit the seals when they were most plentiful in the area, during their northward migration in the spring. The harp seal bones from Phillip's Garden represent specimens killed during the early winter and spring migrations. One can therefore assume that the site was occupied during both of these seasons. While it is relatively straightforward to demonstrate human presence on the site at certain times of year, absence is more difficult to establish. There is always a chance that Dorset groups were storing 
harp seal meat and fat, which would allow them to remain at the site when the harp seals were unavailable. If this was the case, one could reasonably expect them to supplement stored food with other, seasonally available resources.

Some of the fish and bird species in the assemblages can act as seasonal indicators. Non-seal taxa are scarce in the assemblages from Features 49,52 , and 77 , and seasonal migrants are present in only very small numbers (Table 2). Those that are present, Canada goose, White-winged scoter, and Great auk, are all found in the area in the spring. It is most likely that these assemblages represent short-term, seasonal accumulations occurring during the harp seal migrations.
At Feature 2T and Feature 73, the higher percentages of non-seal taxa may indicate activity at periods other than during the spring and early winter harp seal migrations. Unfortunately, the issue is difficult to resolve for Feature 2T because few of the fish and bird species from this assemblage are seasonal migrants, making it difficult to determine a precise seasonal association for the remains. Harp seals play an important role in the Feature 2T assemblage, and their migrations were clearly the main focus of activity. The important non-seal taxa, such as sculpins and ducks, are potentially available year-round (though certain species within these groups are migratory). Herring gull and Great auk, the only seasonal migrants

Table 2. Representation of fish and birds at Phillip's Garden (NISP).

\begin{tabular}{|c|c|c|c|c|c|c|c|}
\hline \multirow[b]{2}{*}{ Taxon } & \multirow[b]{2}{*}{ Common Name } & \multirow[b]{2}{*}{ Available } & \multicolumn{5}{|c|}{ Feature } \\
\hline & & & F 49 & F 52 & F 77 & F 2T & F 73 \\
\hline PICES & Unidentified Fish & $\mathrm{n} / \mathrm{a}$ & - & 4 & 34 & 256 & 623 \\
\hline Cottidae & Sculpin family & all year & - & - & - & 118 & 2 \\
\hline Tautogolabrus adsperus & Cunner & all year & - & - & - & 26 & - \\
\hline Pleuronectiformes & Flounder & all year & - & - & - & 8 & - \\
\hline Pleuronectidae & Right-eye flounder & all year & - & - & - & 4 & - \\
\hline Gadidae & Cod family & all year & - & - & - & 1 & 24 \\
\hline Gadus morhua & Atlantic cod & all year* & - & - & - & - & 19 \\
\hline AVES & Unidentified bird & $\mathrm{n} / \mathrm{a}$ & 59 & 2 & 9 & 245 & 61 \\
\hline Anatinae & Duck subfamily & all year & 27 & - & - & 63 & 8 \\
\hline Branta canadensis & Canada goose & April-Sept. & - & - & 1 & - & 1 \\
\hline Somateria sp. & Common/King eider & all year & 4 & - & - & 22 & 1 \\
\hline Melanitta sp. & Scoter & all year & - & - & - & - & 1 \\
\hline Melanitta fusca & White-winged scoter & Oct.-May & 1 & - & - & - & - \\
\hline Somateria/Melanitta & Eider/Scoter & all year & 29 & - & - & 14 & 5 \\
\hline Lagopus sp. & Willow/Rock ptarmigan & all year & - & - & - & 1 & 1 \\
\hline Lagopus lagopus & Willow ptarmigan & all year & - & - & 1 & - & 1 \\
\hline Laridae & Gull family & all year & 1 & - & 4 & 30 & 14 \\
\hline Larus argentatus & Herring gull & March-August & - & - & - & 3 & - \\
\hline Larus marinus & Great black-backed gull & all year & 1 & - & - & 7 & 3 \\
\hline Uria sp./Alca torda & Murre/Razorbill & April-July & - & - & - & - & 1 \\
\hline Penguinus impennis & Great auk & spring-summer & 1 & - & - & 1 & - \\
\hline Alle alle & Dovekie & Oct.-April & - & - & - & 1 & - \\
\hline Corvus corax & Common raven & all year & - & - & 1 & 1 & 4 \\
\hline TOTAL & & & 123 & 6 & $\mathbf{5 0}$ & 801 & 769 \\
\hline
\end{tabular}

${ }^{*}$ Generally found in deep water, but follow the capelin into shallow near-shore waters in June and July (Templeman 1966). 
among the birds, are both available in spring and summer.

The seasonal information from Feature 73 is also somewhat ambiguous. Like the other features, its large percentage of seal implies occupation centered on the harp seal migrations. There are, however, hints of possible summer activity as well. Cod is the fish most frequently identified in this assemblage. While Atlantic cod are present in Newfoundland waters year-round, they are generally found at depths of over 200 m (Lear 1989). However, in June and July, they follow the spawning capelin in towards shore (Templeman 1966), which would make them more readily available to the occupants of Phillip's Garden. Therefore the presence of cod may indicate an early summer occupation in addition to the main activity in the ठ̊ spring and early winter.

\section{Harp Seal Availability}

The faunal assemblages discussed here all suggest ठำintensive exploitation of harp seal during their early winter and spring migrations. The higher percentages of fish and birds in Features $2 \mathrm{~T}$ and 73 may represent activities that extended into the of summer months, or short-term re-occupations of $\vec{s}$ the site during the summer. The larger proporontions of non-seal taxa may also relate to changes Din the local availability of harp seals. If seals beô came less accessible from the site, the Dorset people may have experienced food shortfalls, leading them to expand the breadth of their diet at ơ Phillip's Garden.

Changes in ice conditions and ocean temperature are probably important limiting factors with respect to harp seals and human hunters. Harp seal migration patterns are determined in large part by the movements of the ice (Sergeant 1991). Harp seal breeding and molting is dependent on the availability of sufficient pack ice, and the animals spend the rest of the year feeding at the ice edge (Sergeant 1991:33-61). Local variation in temperature and wind direction can influence the routing and timing of the harp seal migration. For example, spring winds from the west would force the pack ice onto the west coast of Newfoundland, driving the seals further out to sea and away from Phillip's Garden. Early break-up of the pack ice would precipitate a quick northward migration immediately following the molt, also reducing access to the seals at Phillip's Garden.

Large-scale climate variation in the North Atlantic during the Holocene is linked to solar out- put (Bond et al. 2001) and atmospheric (Hurrell et al. 2001) and ocean circulation (Visbeck 2002). Changes in ocean surface temperature are tied to the North Atlantic atmospheric oscillation (NOA), which dictates climate variability, wind speed and direction, heat and moisture transport, and the number and intensity of storms in the region, especially in the winter (Hurrell et al. 2001). Changes in the NOA affect, among other things, the production of zooplankton and the distributions and populations of marine species (Hurrell et al. 2001). Changes in primary productivity in combination with shifting sea-ice patterns could result in higher rates of harp seal pup mortality and poorer fitness of whelping females. In combination, these conditions could produce an overall decrease in herd size, reducing access to harp seals by human hunters throughout the eastern Canadian Arctic.

There is evidence for climatic changes that may relate to the increase in diet breadth witnessed at Phillip's Garden around 1500 B.P. Terrestrial and marine source chemicals found in the GISP2 ice core from Summit, Greenland, reflect past atmospheric and environmental changes in the mid to high northern latitudes (Mayewski et al. 1993, 1994; O’Brien et al. 1995). Decreased sea salt sodium values in the GISP2 core between 2700 and 1500 B.P. indicate a period of milder climate (O’Brien et al. 1995:1962). At approximately 1500 B.P. there was an increase in sea salt sodium, indicating climatic cooling in the marine source regions for the GISP2 core. This also marks the beginning of an increase in the ratio of non-sea salt calcium to non-sea salt magnesium, indicating changing circulation patterns over northern terrestrial regions (O’Brien et al. 1995). However, other GISP2 chemical indicators such as non-sea salt potassium do not show any marked change at this time. This probably relates to the fact that over the course of the Holocene, climate change occurred on an increasingly regional basis (O'Brien et al. 1995:1963). Closer to Phillip's Garden, chironomid (midge) remains from Bass Pond, near Port au Choix, provide a good proxy indicator of summer pond water temperatures. They show a steady increase in temperature beginning at about 1600 B.P., roughly 100 years before the change in subsistence patterns at Phillip's Garden, and reaching a maximum at about 1200 B.P. (Bell et al., in press; Rosenberg 1998). This is the largest increase in temperature registered in the pond in the last 5,000 years. Trevor Bell (personal communication 2002) has suggested that this warming trend may 
relate to decreased cloud cover and fog as a result of a decrease in the amount of sea ice in the region. Thus, subsistence change at Phillip's Garden took place during a shift in northern latitude atmospheric circulation patterns, and shortly after the onset of a local climatic warming.

\section{Discussion}

The Dorset occupation of the island of Newfoundland ended around 1200 B.P., shortly after the abandonment of Phillip's Garden. The Dorset disappearance from the island has often been blamed on a marked decrease in the availability of harp seals. Tuck and Pastore (1985; Pastore 1986) were the first to suggest that the failure of the harp seal hunt might have triggered a series of events which brought about the extinction of the Dorset in Newfoundland. More recently, Renouf and her colleagues have suggested that the Dorset left the island following a period of climatic warming that was detrimental to the harp seal hunt (Bell et al. in press; Renouf 1993:206-207). The faunal data presented here provide the first direct faunal evidence related to this hypothesis, and the marked increase in non-seal taxa through time at Phillip's Garden appears to lend it some support.

At present any interpretations of Dorset subsistence patterns in Newfoundland must remain tentative. This is due to the paucity of direct evidence, in the form of preserved faunal remains, for subsistence practices on the island. Dorset settlement and subsistence patterns in Newfoundland have not been formally modelled until fairly recently. The existing models, proposed by Robbins (1985), Pastore (1986), and Schwarz (1994) rely heavily on site location information. They may over-emphasize the importance of the harp seal in Dorset subsistence on the island because they have been strongly influenced by the single large published faunal assemblage from Phillip's Garden, which, given its unique location, may not be representative of activities across the island.

Seasonal variability is a universal component of high-latitude hunter-gatherer subsistence economies, and models of the Dorset subsistence economy in Newfoundland assume that different types of site locations represent different seasons of activity. To simplify, they suggest spring seal hunting at the outer coast, summer exploitation of a wide range of species from inner-coastal locations, fall caribou hunting in the interior, and a possible return to the outer coast for the winter
(Schwarz 1994). Robbins (1985) also suggests that there were regional differences in Dorset subsistence practices on the island. None of these models, however, include the possibility of temporal variation, implying that subsistence practices on the island were static through time.

A recently excavated faunal assemblage from the Dorset site of Peat Garden North (Hartery and Rast 2001; Reader 1998), 60 km north of Phillip's Garden (Fig. 1), presents the first direct evidence concerning the degree of seasonal subsistence variation on the island. The site has produced a single charcoal-based radiocarbon date of $1570 \pm 60$ B.P. (Beta-113160; Hartery and Rast 2001). The faunal assemblage includes several different seal species, caribou, beaver, and a range of birds indicating a diversified subsistence strategy at this location (Murray 1998, 2000; see Table 3). Based on the high frequency of goose remains containing medullary bone, Murray (1998:3, 2000:6) argues that the site represents a warm season occupation. Seal remains comprise $43 \%$ of this assemblage, indicating that while seal species were still important to the hunters at Peat Garden North, Dorset subsistence practices were less focused on harp seal at this site than at Phillip's Garden. Clearly, the summer subsistence activities reflected here are far more generalized than the early winter and spring activities represented at nearby Phillip's Garden.

In addition to the seasonal subsistence variation postulated for the Dorset in Newfoundland (Pastore 1986; Robbins 1985; Schwarz 1994) and demonstrated in the composition of the faunal assemblages from Phillip's Garden and Peat Garden North, Robbins (1985) has also suggested regional subsistence variation for the Dorset on Newfoundland. Based on the availability of different prey species in different parts of the island, he suggests that Dorset subsistence focused on seals on the west coast and the Northern Peninsula, due to the Dorset's ready access to the migratory harp seal herds. He suggests a similar reliance on seal species on the northeast coast of the island, which provides access to the breeding grounds of the Front harp seal herd. He proposes a more varied, generalized subsistence strategy involving harbor and grey seals, caribou, fish, and birds on the south coast of the island and on the isthmus of the Avalon Peninsula, where harp seals are unavailable. The notion of regional variability within the Newfoundland Dorset is reinforced by the presence of distinct regional expressions of Dorset lithic technology on the island (LeBlanc 2000b; Robbins 1985). 
Table 3. Representation of identified taxa at Peat Garden North.

\begin{tabular}{lrr}
\hline Taxon & NISP & \% of identified material \\
\hline Unidentified Fish & 22 & 0.9 \\
Unidentified Bird & 447 & 18.5 \\
Duck/Goose & 654 & 27.0 \\
Goose & 81 & 3.3 \\
Duck & 62 & 2.6 \\
Caribou & 102 & 4.2 \\
Small/Medium terrestrial mammal & 27 & 1.1 \\
Harbor seal & 3 & 0.1 \\
Harp seal & 41 & 1.7 \\
Hooded seal & 10 & 0.4 \\
Unidentified seal & 969 & 40.1 \\
\hline TOTAL & $\mathbf{2 , 4 1 8}$ & $\mathbf{9 9 . 9}$ \\
\hline
\end{tabular}

Phillip's Garden obviously represents only 茄one aspect of Dorset subsistence strategies in NewFfoundland. However, the increasing proportion of offish and birds in the midden assemblages studied here indicates marked changes in subsistence ¿ิ practices at the site through time. In addition to ithe seasonal and regional variation that has already been postulated, this highlights the impor\&tance of considering temporal variability in any z future modelling of Dorset subsistence activities in 苍Newfoundland.

Б八

Acknowledgements. Hodgetts conceived and wrote Ethis article, with written input from Murray. Re$\Xi$ nouf, McCuaig-Balkwill, and Howse all con\& tributed data to the project. Murray generated the Peat Garden North data. The authors are greatly indebted to Anne Rick who identified some of the Phillip's Garden faunal material. Thanks also to Jim Tuck and an anonymous reviewer for their comments on earlier drafts of this paper. This research was funded by a SSHRC post-doctoral fellowship awarded to Hodgetts. The Port au Choix excavations were supported by three SSHRC standard research grants and Parks Canada funding awarded to Renouf, and by grants to Renouf and to Hodgetts from the Institute for Social and Economic Research at Memorial University, the J. R. Smallwood Foundation for Newfoundland and Labrador Studies, and the Department of Tourism, Culture and Recreation, Government of Newfoundland and Labrador. Analysis of the faunal remains from Features 49, 52, and 2T at Phillip's Garden was supported by the Canadian Museum of Nature. Analysis of the Peat Garden North fauna was funded by an award to Murray from the Big Droke Pre/Historic Cultures Foundation, Bird Cove, Newfoundland, and further supported by the College of Liberal Arts, University of Alaska Fairbanks.

\section{End Notes}

1. Feature 49 was excavated by Renouf (2002) and the faunal material was identified by McCuaigBalkwill (Renouf 2002).

2. Feature 52 was excavated by Renouf (2002) and McCuaig-Balkwill identified the faunal material (Renouf and Murray 1999).

3. Feature 77 was excavated by Hodgetts (2002). Hodgetts and Howse identified the faunal material.

4. Feature 2T was excavated by Renouf (1987). McCuaig-Balkwill identified the faunal material.

5. Feature 73 was partially excavated by Renouf in 1992 (Renouf 2002). The recovered faunal material was identified by Anne Rick of the Zooarchaeological Identification Centre, Canadian Museum of Nature. Hodgetts (2002) further excavated the midden in 2001 and identified all resulting faunal material.

\section{References Cited}

Amorosi, Thomas, James Woollett, Sophia Perdikaris, and Thomas McGovern

1996 Regional Zooarchaeology and Global Change: Problems and Potentials. World Archaeology 28(1):126-157.

Bell, Trevor, Joyce B. MacPherson, and M. A. P. Renouf In "Wish You Were Here ..." a Thumbnail press Portrait of the Great Northern Peninsula 1000 A.D. In Vinland Revisited: The Norse World at the Turn of the First Millennium. Shannon Lewis-Simpson, ed. St. John's: Historic Sites Association of Newfoundland and Labrador.

Bond, Gerald, Bernd Kromer, Juerg Beer, Raimund Muscheler, Michael N. Evans, William Showers, Sharon Hoffmann, Rusty Lotti-Bond, Irka Hajdas, 
and Georges Bonani

2001 Persistent Solar Influence on North Atlantic Climate during the Holocene. Science 294:2130-2136.

Bronk Ramsay, Christopher

2000 Oxcal Program v. 3.5 URL http://www.rlaha.ox.ac.uk/oxcal/oxcal.htm.

Cruz-Uribe, K., and R. G. Klein

1994 Chew Marks and Cut Marks on Animal Bones from the Kasteelberg B and Dune Field Midden Later Stone Age Sites, Western Cape Province, South Africa. Journal of Archaeological Science 21:35-49.

Eastaugh, Edward J. H.

2002 On the 2001 Field Season at Point Riche, Port au Choix National Historic Site. On file at Historic Resources Branch, Atlantic Region, Parks Canada, Halifax, N.S.

Erwin, John C.

1995 An Intrasite Analysis of Phillip’s Garden: A Middle Dorset Palaeo-Eskimo Site at Port au Choix, Newfoundland. Master's Thesis, Department of Anthropology, Memorial University of Newfoundland.

Harp, Elmer

1976 Dorset Settlement Patterns in Newfoundland and Southeastern Hudson Bay. In Eastern Arctic Prehistory: Paleoeskimo Problems. M. S.

Maxwell, ed. Pp. 119-138. Memoirs of the Society for American Archaeology, Washington, D.C.

Hartery, Latonia and Tim Rast

2001 Bird Cove Archaeology Project, 2000 Field Season: Final Report. On file at the Provincial Archaeology Office, Culture and Heritage Division, Department of Tourism, Culture and Recreation, Government of Newfoundland and Labrador.

Hodgetts, Lisa M.

1999 Animal Bones and Human Society in the Late Younger Stone Age of Arctic Norway. Ph.D. dissertation, Department of Archaeology, University of Durham.

2002 On the 2001 Excavations at Phillip's Garden, Port au Choix National Historic Site. On file at the Historic Resources Branch, Atlantic Region, Parks Canada, Halifax.

In Dorset Paleoeskimo Harp Seal Exploitation press a at Phillip's Garden (EeBi-1), Northwestern Newfoundland. In The Aboriginal Exploitation and Cultural Importance of Sea Mammals. Gregory Monks, ed. Oxford: Oxbow Books.

In Using Bone Measurements to Determine press b the Season of Harp Seal Hunting at Phillip's Garden. Newfoundland Studies.

Hurrell, James W., Yochanan Kushnir, and Martin Visbeck

2001 The North Atlantic Oscillation. Science 291:603-606.
Lear, William Henry

1989 Atlantic Cod. Underwater World Series, no. 38a. Communications Directorate, Department of Fisheries and Oceans, Ottawa.

LeBlanc, Sylvie

1996 A Place with a View: Groswater SubsistenceSettlement Patterns in the Gulf of St. Lawrence. Master's thesis, Department of Anthropology, Memorial University of Newfoundland.

2000a Groswater Technological Organization: A Decision-Making Approach. Arctic Anthropology 37(2):23-37.

2000b Middle Dorset (1900-1100 BP) Regional Variability on the Island of Newfoundland and in Saint-Pierre et Miquelon. In Identities and Cultural Contacts in the Arctic. Martin Appelt, Joel Berglund, and Hans Christian Gulløv, eds. Pp 97-105. Copenhagen: Danish Polar Centre Publications.

Linehan, Dolores A.

1990 The Analysis and Discussion of Four Midden Squares at Phillip's Garden, Port au Choix, Newfoundland. B. A. Honors thesis, Department of Anthropology, Memorial University of Newfoundland.

Lyman, R. L.

1991 Prehistory of the Oregon Coast. San Diego: Academic Press.

Maxwell, Moreau S.

1985 Prehistory of the Eastern Arctic. Orlando: Academic Press.

Mayewski, P. A., L. D. Meeker, S. Whitlow, M. S. Twickler, M. C. Morrison, R. B. Alley, P. Bloomfield, and K. Taylor

1993 The Atmosphere during the Younger Dryas. Science 261:195-197.

Mayewski, P. A., L. D. Meeker, S. I. Whitlow, M. S. Twickler, M. C. Morrison, P. Bloomfield, G. C. Bond, R. B. Alley, A. J. Gow, P. M. Grootes, D. A. Meese, M. Ram, K. C. Taylor, and W. Wumkes

1994 Changes in Atmospheric Circulation and Ocean Ice Cover over the North Atlantic during the Last 41,000 Years. Science 263:1747-1751.

McGhee, Robert

1990 Canadian Arctic Prehistory. Hull: Canadian Museum of Civilization.

1996 Ancient People of the Arctic. Vancouver: University of British Columbia Press.

Murray, Maribeth S.

1992 Beyond the Laundry List: The Analysis of Faunal Remains from a Dorset Dwelling at Phillip's Garden (EeBi-1), Port au Choix, Newfoundland. Master's thesis, Department of Anthropology, Memorial University of Newfoundland. 
1998 Faunal Report: Dorset Palaeoeskimo Component at Peat Garden North Site (EgBf-18), Bird Cove, Newfoundland, 1997 Field Season. On file at the Provincial Archaeology Office, Culture and Heritage Division, Department of Tourism, Culture, and Recreation, Government of Newfoundland and Labrador.

2000 On the Archaeofauna from Peat Garden 1999 Excavations. On file at the Provincial Archaeology Office, Culture and Heritage Division, Department of Tourism, Culture, and Recreation, Government of Newfoundland and Labrador.

O’Brien, S. R., P. A. Mayewski, L. D. Meeker, D. A. Meese, M. S. Twickler, and S. I. Whitlow

1995 Complexity of Holocene Climate as Reconstructed from a Greenland Ice Core. Science 270:1962-1964.

P.Parsons, D. G.

ㄱ1980 A Review of Shrimp Resources in the Gulf of St. Lawrence. Report for the Gulf Shrimp Advisory Committee. Department of Fisheries and Oceans Canada.

ภิPastore, Ralph T.

స1986 The Spatial Distribution of Late Palaeo-Eskimo

กิ Sites on the Island of Newfoundland. In PalaeoEskimo Cultures in Newfoundland, Labrador and Ungava. Pp. 125-134. Reports in Archaeology, no. 1. St. John's: Memorial University of Newfoundland.

Reader, David A.

1998 The 1997 Archaeological Survey of the Bird Cove Area, Northwestern Northern Peninsula, Newfoundland. On file at the Provincial Archaeology Office, Culture, and Heritage Division, Department of Tourism, Culture, and Recreation, Government of Newfoundland and Labrador.

Renouf, M. A. P.

1987 Archaeological Excavations at the Port au Choix National Historic Park: Report of the 1986 Field Activities. On file at Historic Resources Branch, Parks Canada, Atlantic Region, Halifax, N.S.

1993 Palaeoeskimo Seal Hunters at Port au Choix Northwestern Newfoundland. Newfoundland Studies 9(2):185-212.

2000 Symbolism and Subsistence: Seals and Caribou at Port au Choix, Northwestern Newfoundland. In Animal Bones, Human Societies. P. A. Rowley-Conwy, ed. Pp. 65-73. Oxford: Oxbow Press.
2002 Archaeology at Port au Choix, 1990 to 1992 Excavations. Occasional Papers in Northeastern Archaeology, no. 12. St. John's: Copetown Press.

Renouf, M. A. P. and Maribeth S. Murray

1999 Two Winter Dwellings at Phillip's Garden, A Dorset Site in Northwestern Newfoundland. Arctic Anthropology 36:118-132.

Robbins, Douglas T.

1985 Stock Cove, Trinity Bay: The Dorset Eskimo Occupation of Newfoundland from a Southeastern Perspective. Master's thesis, Department of Anthropology, Memorial University of Newfoundland.

Rosenberg, S.

1998 Chironomids and Their Relationship to the Archaeological Record and Sea Level Change at Bass Pond, Newfoundland, Canada. B.Sc. Honors thesis, Okanagan University College.

Schwarz, Frederick A.

1994 Paleo-eskimo and Recent Indian Subsistence and Settlement Patterns on the Island of Newfoundland. Northeast Anthropology 47:55-70.

Sergeant, David E.

1991 Harp Seals, Man, and Ice. Canadian Special Publications of Fisheries and Aquatic Sciences, no. 114. Department of Fisheries and Oceans, Ottawa.

Shahidi, F., J. Synowiecki, R. Amarowicz, and U. Wanasundara

1994 Omega-3 Fatty Acid Composition and Stability of Seal Lipids. In Lipids in Food Flavors.

Chi-Tang Ho and Thomas G. Hartman, eds. Pp. 233-243. ACS Symposium Series 558.

Stuiver, M., P. J. Reimer, and T. F. Braziunas

1998 High-Precision Radiocarbon Age Calibration for Terrestrial and Marine Samples. Radiocarbon 40(3):1127-1151.

Templeman, Wilfred

1966 Marine Resources of Newfoundland. Fisheries Research Board of Canada, Ottawa.

Tuck, James A. and Ralph T. Pastore

1985 A Nice Place to Visit, but. . . . Prehistoric Human Extinctions on the Island of Newfoundland. Canadian Journal of Archaeology 9:69-79.

Visbeck, Martin

2002 The Ocean's Role in Atlantic Climate Variability. Science 297:2223-2224. 